\title{
Currículo, universalismo e relativismo: Uma discussão com Jean-Claude Forquin
}

\author{
Tomaz Tadeu da Silva*
}

\begin{abstract}
RESUMO: O texto discute a conferência do professor JeanClaude Forquin, proferida em 17 de junho de 1997, por ocasião do seminário internacional comemorativo dos 25 anos dos cursos de pós-Graduação da Faculdade de Educação da Universidade Federal do Rio de Janeiro. Questiono, sobretudo, a argumentação desenvolvida pelo conferencista em favor de um currículo no qual as "ciências" deveriam figurar como a representação da universalidade do conhecimento, enquanto outras disciplinas, menos "exatas" e mais "culturais", apareceriam como a expressão da relatividade epistemológica. Apresento, em contraposição, uma posição que vê ambos os "tipos" de conhecimento como construções sociais e culturais, sujeitos, igualmente, ao questionamento e à crítica.
\end{abstract}

Palavras-chave: Universalidade, relativismo, currículo, cultura, multiculturalismo

I.

O professor Forquin parece aceitar, sem problemas, a premissa dos dois relatórios franceses sobre educação $(1985,1988)$, da separação entre pensamento científico (significando ciências exatas, suponho) e ciências humanas, o que supõe, por sua vez, uma separação nítida entre natureza e cultura, entre objeto e sujeito. Essa separação, que parece retirar a ciência do campo do cultural e do social, tem sido questionada a partir de várias perspectivas (do feminismo aos movimentos ecológicos),

Professsor da Faculdade de Educação/UFRGS, Home page: www.tomaz.net. E-mail: ttadeu@yahoo.com. 
todas as quais argumentam, basicamente, que, longe de refletir qualquer tipo de universalismo, o pensamento e a atividade científica estão inextricavelmente vinculados com relações sociais. Numa época em que as conexões entre a atividade científica e processos de dominação de todo tipo são, mais do que nunca, evidentes na história e no cotidiano, a sustentação desse pressuposto parece, para dizer o mínimo, surpreendente. É importante questionar esse primeiro pressuposto do professor Forquin porque ele vai permanecer implícito no resto de sua discussão: o universalismo da ciência, dado como aceito no início da sua discussão, não será nunca questionado. Aqui, a ciência, inquestionável, o reino do universalismo; ali, a cultura, campo de um possível (e relativo) relativismo, espaço onde se pode, limitadamente, atendidos certos critérios universalistas, fazer alguma concessão à variabilidade e à invenção social. Em nenhum dos dois, como veremos, há qualquer consideração da presença de relações de poder e muito menos da possibilidade de que os dois possam estar vinculados precisamente por essas relações. Contrariamente ao pressuposto do professor Forquin, a partir de muitas perspectivas, hoje, o universalismo da ciência, longe de ser uma premissa tranqüilamente aceita, é precisamente o que precisa ser questionado.

II.

Essa visão epistemológica tem, imediatamente, como conseqüência, um dualismo curricular pelo qual o currículo ficaria dividido entre dois campos: o da ciência e o da cultura. No primeiro se localizaria o ensino das ciências, presumidamente feito de forma objetiva, inquestionável, neutra, imparcial. No outro, o ensino da cultura, no qual, segundo o relatório Bourdieu, "se prestaria atenção à pluralidade dos modos de vida e das tradições culturais". Presume-se que num lado desse currículo esquizofrênico esteja em formação um ser cognoscente cuja atitude característica é a aceitação passiva dos fatos da ciência tais como eles são; no outro, um ser cultural cuja virtude principal consiste na aceitação da pluralidade das culturas. De um lado desse currículo cartesiano, a natureza e o objeto, os fatos, a objetividade; do outro, a cultura e o sujeito, a variabilidade social, a subjetividade. Num lado da divisória, presumidamente nobre, superior, o universalismo das ciências; no outro, presumidamente secundário, inferior, o relativismo das culturas. O professor Forquin não vê nisso antagonismo, mas complementaridade. Mas se, ao contrário, concebermos tanto a ciência quanto a cultura como relações sociais, não haverá nem antagonismo nem 
complementaridade, mas uma mesma atitude crítica e de questionamento diante de qualquer resultado ou processo de invenção humana.

III.

A dicotomia "ciência versus cultura", estabelecida no raciocínio do professor Forquin, retorna, mais adiante, na dicotomia "relativismo epistemológico versus relativismo cultural". O relativismo epistemológico estaria relacionado aos "saberes estritos", enquanto o relativismo cultural estaria ligado a "valores estéticos, atitudes morais e sociais...". O texto do professor Forquin não é claro a esse respeito. Mas adivinha-se que um relativismo cultural, estando limitado a essa esfera dos valores, poderia ser aceito, enquanto um relativismo epistemológico, dizendo respeito ao saber propriamente dito, não seria aceitável. Apenas no primeiro caso estamos tratando de "elementos cognitivos"; no segundo, temos apenas "elementos culturais". No primeiro caso, teríamos a oposição "relativismo versus racionalismo"; no segundo, a oposição "relativismo e universalismo". A divisão que o professor Forquin faz entre essas duas oposições nos faz presumir, embora não esteja claro, que apenas a segunda seria legítima, enquanto a primeira estaria fora de questão. Supostamente, pode-se discutir os valores culturais, o que autoriza uma possível posição relativista nesse campo. Os saberes, como elementos cognitivos, racionais, não são passíveis de questionamento: como se pode presumir da oposição - não explicada - "relativismo versus racionalismo", aqui, relativismo é o equivalente de irracionalismo. Como se pode ver, trata-se apenas de uma reelaboração da dicotomia entre ciência e cultura anteriormente examinada, que reforça a posição do professor Forquin em favor de um currículo dividido.

IV.

Como uma nota talvez secundária, parece no mínimo enigmática a observação do professor Forquin ao referir-se, de forma aparentemente aprovadora, aos dois relatórios franceses sobre educação. Diz o professor Forquin:

Quando os autores dos dois relatórios... evocam... a "lição do relativismo" que as ciências históricas ou humanas poderiam nos dar, eles não estão sugerindo (ou, ao menos, necessariamente) que possa estar, ela própria, marcada pelo caráter do relativismo, que os saberes ensinados ou ensináveis nas escolas sob o rótulo de 
ciências humanas sejam, eles próprios, "construções sociais" cultural ou politicamente "enviesadas" (...)

A continuação talvez sirva para esclarecer melhor o significado dessa afirmação:

Marquemos (...) a diferença entre o relativismo considerado como um objeto ou um tema de ensino e o relativismo considerado como característica interna e de certo modo estrutural dos saberes ensinados.

Quer isso dizer que mesmo as ciências humanas, mesmo o campo cultural, estão fora de questionamento? O que significa aceitar o relativismo como "objeto ou tema de ensino", mas não aceitar o relativismo enquanto "característica interna dos saberes ensinados"? Que relativismo sobraria, então, para ser ensinado?

V.

Na parte final de seu texto, o professor Forquin tenta definir o que entende por universalismo no contexto do currículo escolar. Numa primeira tentativa, o professor Forquin equaciona universalismo com "generalidade". A cultura escolar seria universalizante porque baseada em competências e saberes "gerais, organizadores e integradores". Como o professor Forquin não entra em detalhes sobre quais seriam esses saberes gerais, fica difícil discutir sua pretensa universalidade. Especulemos, entretanto. Em primeiro lugar, Forquin mistura saberes e competências, elementos sobre os quais a questão da "generalidade" parece se aplicar de forma diferente. No caso dos saberes e conhecimento, dada a complexidade e a diversidade da sociedade e do conhecimento, hoje, fica difícil decidir quais conhecimentos e saberes teriam essa propriedade de "generalidade" advogada por Forquin. Dada as acirradas disputas por autoridade e legitimidade no campo do conhecimento, da ciência, da cultura, sob quais critérios se decidiria quais saberes seriam suficientemente gerais para receberem a qualificação definida por Forquin? No caso das competências, a situação parece ainda mais complicada, pois, o exercício de competências, habilidades e capacidades específicas não parece ser facilmente separável dos materiais, objetos e contextos sobre os quais se aplicam. Em suma, o equacionamento de universalidade com generalidade parece não resolver o problema da 
definição do que seria universal. Ainda é necessário definir o que é "geral", e como se define o que é "geral". Numa segunda tentativa, Forquin traduz "geral" por "elementar". Mas, outra vez, a argumentação é circular, pois "elementar" são "ao mesmo tempo as coisas simples mais fundamentais, que constituem a chave de todos os saberes ulteriores, as coisas que todo mundo deve poder aprender porque todo mundo as compreende", ou seja, é elementar aquilo que é "universal", no sentido normativo de que é "o que todo mundo deve aprender". Um tal raciocínio circular só poderia terminar com uma afirmação categórica para a qual Forquin convoca nada menos que Régis Debray, talvez para dar uma autoridade "revolucionária" a uma afirmação bem pouco revolucionária: "os elementos primeiros são incontestáveis e transmissíveis a todo ser razoável com a única condição de que se lhes preste atenção." Incontestáveis? Ser razoável? Basta "prestar atenção"? Cada palavra dessa frase me parece altamente contestável! Um pensamento tão fechado parece precisamente contradizer, ponto por ponto, o suposto caráter "aberto e flexível" da cultura escolar, aduzido por Forquin poucas linhas antes dessa citação de Debray.

Vl.

Mas o professor Forquin nos obriga a mais uma divisão: entre o universalismo dos saberes elementares da escola elementar e o universalismo da "exemplaridade absoluta e intemporal dos modelos humanos e dos modelos expressivos consignados de uma vez por todas num repertório e numa tradição". "Absoluta"? Por que absoluta? "Intemporal"? Em que região, fora da história e do tempo, se escondem esses modelos humanos? "Modelos humanos"? Sob quais critérios se decidem quais são esses modelos humanos? Fora de uma concepção essencialista de sujeito, como fixar esses modelos humanos? Quem decide quais são esses modelos? "Tradição"? Qual tradição? "De uma vez por todas"? Em que momento do movimento cultural se decide esse "de uma vez por todas"? E, de novo, quem decide? A explicitação do que constituiriam esses "modelos" nos ajuda a compreender melhor qual a definição de universalismo do professor Forquin:

Assim, as obras clássicas da arte e da literatura constituem o conservatório do que merece ser ensinado e glorificado, o círculo encantado fora do qual não há formação do espírito, porque todo o resto cai na categoria do trivial ou do comum. 
Dada a variedade do potencial de realização do humano, evidentes na história e na cultura contemporânea, essa descrição tão estreita e tão particular de modelo do humano e da capacidade humana, que deixa de fora até mesmo outras capacidades humanas tão canônicas quanto as citadas, dificilmente pode ser qualificada como universal. Trata-se, em qualquer caso, de um universalismo bastante peculiar, para dizer o mínimo.

VII.

Dada a concepção de universalismo de Forquin, é surpreendente que ele possa aceitar qualquer tipo de multiculturalismo. Mas sua concepção de multiculturalismo em educação é, ponto por ponto, coerente com sua definição de universalismo. Para ele, seguindo Lynch, o multiculturalismo deve se concentrar no cultivo de "meta-valores", "critérios de escolha verdadeiramente fundamentais que só podem ser os critérios de funcionalidade, de racionalidade e de universalidade". Para Forquin,

a idéia de respeito às culturas supõe a existência de um ponto de vista exterior às próprias culturas e a adoção de critérios com caráter de universalidade.

Como conseqüência, uma educação intercultural

se pode conceber a atenção e o respeito que indivíduos de diferentes culturas merecem se ela for capaz, antes de tudo, de reconhecêlos como seres humanos genéricos, que apresentam vocação transcultural para racionalidade.

Ainda na concepção de Forquin, a

escola não pode mais ignorar os aspectos "contextuais" da cultura, (...), mas deve se esforçar por privilegiar o que há de mais fundamental, de mais constante, de mais incontestável e, por conseguinte, de menos "cultural" (...) nas manifestações da cultura humana.

A dificuldade básica consiste em definir esse "ponto de vista exterior às próprias culturas". Onde, precisamente, se situa esse ponto? Voltamos aos "modelos humanos", mencionados anteriormente por Forquin, só que, agora, à intemporalidade se acrescenta a transcendentalidade extracultural. 
Como Forquin não define com precisão "esse ponto de vista exterior", temse o direito de suspeitar que esse ponto de vista exterior coincide, na verdade, com as concepções culturais dominantes, sobretudo se consideramos suas definições de "modelo humano" anteriormente fornecidas. Como em outros campos da atividade humana, parece que também aqui aquilo que é definido como universal é apenas um ponto de vista particular que, nessa operação de autodefinição, oculta seu próprio particularismo. O multiculturalismo do professor Forquin reduz-se, assim, ao ensino do mesmo e da norma sob o disfarce do transcendente, do transcultural e do universal.

VIII.

Tendo me concentrado pontualmente em alguns dos argumentos de Forquin, gostaria agora de fazer comentários mais gerais. Não tenho certeza de que a discussão universalismo/relativismo, tal como em geral tem sido colocada, tenha algum sentido. Ela só faz sentido dentro de uma perspectiva fundacional, dentro de uma perspectiva que se baseie nalgum conjunto transcendental de princípios primeiros, originais. Eu enfatizaria, em vez disso, uma perspectiva posicional, uma perspectiva enunciativa. Nessa perspectiva, há uma inversão da pergunta. A questão não é: quais são os universais?, mas: como se definem universais?, quem está em posição de defini-los? Nessa perspectiva, os universais não são a solução, mas o problema. A demonstração de que a discussão sobre universalismo/relativismo é uma questão posicional, enunciativa, é dada pelo fato de que não se conhece nenhum grupo cultural ou social que reivindique a posição "relativista": o "relativismo" não é nunca uma reivindicação, é sempre uma acusação dirigida ao outro. Em troca, são universais os valores, os critérios, os saberes daquele que enuncia, daquele que pronuncia o universalismo. É universal aquilo que eu, em posição enunciativa de poder que me permite fazer isso, declaro como universal. Em suma, a questão do universalismo/relativismo não é uma questão epistemológica, mas uma questão política. Em termos sociológicos, eu diria que os universais não explicam, eles é que têm de ser explicados. Além disso, é necessário também reconhecer a implicação dos universalismos na própria constituição da diferença. Não é que tenhamos diferenças preexistentes, de um lado, e elementos universais, de outro. Os universais são, eles próprios, elementos constituintes das estratégias discursivas pelas quais as diferenças são enunciadas. Em certo sentido, os "universais" não podem ser a superação das diferenças, porque, como elementos 
de normalização, eles estão na origem da produção das diferenças. Não haveria diferença se não houvesse "universais". O universal não é o oposto, a superação da diferença; o universal faz a diferença. O universalismo é um processo enunciativo que divide o social entre "nós" (universalistas) e "eles" (particularistas, relativistas).

IX.

Forquin termina dizendo que

o papel da escola, o papel dos "ensinantes da cultura", (...) é dar a cada um a possibilidade de compreender, como uma polifonia cristalina, as múltiplas vozes que se ouvem, de tempos em tempos, nos mais diferentes cantos do mundo.

Caberia acrescentar que muitas dessas vozes são, na verdade, gritos; que são vozes que não se ouvem apenas de tempos em tempos, mas o tempo todo; e que, finalmente, não há nenhuma necessidade de fazê-las soar como uma "polifonia cristalina": deixemos que elas se manifestem, em vez disso, em sua incômoda mas transformativa cacofonia.

Recebido para publicação em Julho de 2000.

\section{Curriculum, universalism and relativism:}

\section{A discussion with Jean-Claude Forquin}

ABSTRACT: This article discusses a lecture given by Professor Jean-Claude Forquin on June 17, 1997, at the international seminar celebrating the $25^{\text {th }}$ anniversary of the Graduate Courses of the Faculty of Education (Federal University of Rio de Janeiro). Basically, I question Forquin's argument in favor of a curriculum where the so-called "sciences" would appear as representing a supposed universality of knowledge, whereas the other, less "precise" and more "cultural" disciplines would be seen as the expression of epistemological relativity. My position, in contrast, is that both "types" of knowledge should be viewed as social and cultural constructions, and are therefore subject to the same questioning and criticism.

Key words: Universality, relativism, curriculum, culture, multiculturalism 